\title{
Shared Vowels in English Loanwords in Arabic: Variation in Similarity-Based Adaptation \\ https://doi.org/10.33806/ijaes2000.22.1.11
}

\author{
Musa Alahmari \\ King Khalid University, KSA
}

Received on 21.4.2021

Accepted on 9.9.2021

Published on 1.1.2022

\begin{abstract}
This paper investigates vowel adaptation in English-based loanwords by a group of Saudi Arabic speakers, concentrating exclusively on shared vowels between the two languages. It examines 5 long vowels shared by the two vowel systems in terms of vowel quality and vowel duration in loanword productions by 22 participants and checks them against the properties of the same vowels in native words. To this end, the study performs an acoustic analysis of 660 tokens (loan and native vowel sounds) through Praat to measure the first two formants (F1: vowel height and F2: vowel advancement) of each vowel sound at two temporal points of time (T1: the vowel onset and T2: the peak of the vowel) as well as a durational analysis to examine vowel length. It reports that measurements of the first two formants of vowels in native words appear to be stable during the two temporal points while values of the same vowel sounds occurring in loanwords are fluctuating from T1 to $T 2$ and that durational differences exist between loanword vowels in comparison with vowels of native words in such a way that vowels in native words are longer in duration than the same vowels appearing in loanwords.
\end{abstract}

Keywords: adaptation, loanwords, nativization, perception, similarity

\section{Introduction}

The integration of loanwords from a source language (L2, the foreign/donor language) into a recipient language ( $\mathrm{L} 1$, the native/borrower language) usually requires the loanwords to undergo various phonological-morphological processes, generally referred to as 'adaptation'. In general, the process of adaptation is based on similarity and how categories can be distinguished from one another by L1 native speakers (i.e., borrowers). Nonetheless, the issue of how adaptation of loanwords is triggered by the requirements of conformity to the recipient language system is a matter of substantial research on a number of various languages in the literature (e.g., Silverman, 1992; Davis, 1994; Yip, 2002; Haunz, 2004; LaCharité and Paradis, 2005; Davis and Cho, 2006; Miao, 2006; Kenstowicz, 2007; Lee, 2009; Kang, 2011; Paradis and LaCharité, 2011; Tu, 2013; Guba, 2016; Natvig, 2017; Boberg, 2020; Alahmari, 2021). In order to account for adaptation in the study of loanwords, phonologists and phoneticians have proposed different models that can be generally classified into two major approaches: the phonological approach and the phonetic approach. The phonological approach advocates the 
view that loanword adaptation is primarily representational based on abstract grammatical representations and structural constraints that are grounded in the recipient's language phonological system (LaCharité and Paradis, 2005; Paradis and LaCharite, 1997 2011). The phonetic approach, on the other hand, marks the view that adaptation in loanwords is primarily perceptual based on acoustic qualities and auditory salience of sounds that are grounded in the recipient's language perceptual system (Peperkamp and Dupoux, 2003; Peperkamp, 2005).

The purpose of the present study is to focus on vowel adaptation in Englishbased loanwords as produced by Arabic speakers, with a special focus on shared/similar vowels and not foreign/different ones, excluding extra linguistic factors such as orthography and contact. Generally speaking, shared sounds between L1 and L2 in the study of loanword phonology are expected to be simpler for adaptation than different foreign sounds premised on the assumption that adaptation is in its essence based on similarity. Nonetheless, this assumption has not been sufficiently examined, and it seems to be implicitly taken for granted. While it stands to reason that shared sounds should not be problematic for borrowers as is the case with foreign sounds, the present study shows that even for shared and similar sounds between L1 and L2, differences still exist in loan sounds adaptation. More specifically, the study investigates how shared vowels in the two vowel inventory systems of Arabic and English are processed and produced by borrowers. This is carried out through an acoustic analysis of vowel properties obtained from the productions of Arabic speakers of English loanwords which are then checked against the same vowel properties in native words through Praat (Boersma and Weenink, 2021). Given that English and Arabic vowel systems are significantly different from one another, with English being a language with a rich vowel system compared to the far simpler Arabic vowel system, the present study does not focus on differences between these systems. Rather, it sheds light on how the few shared vowel sounds are mapped and matched by speakers, and whether speakers attend to phonetic or phonological features of sounds during their matchings and productions of similar shared sounds. No studies, to the best of my knowledge, have thoroughly explored such an issue before. As such, it will be shown that vowels occurring in native words (henceforth native vowels) compared to the same vowels appearing in loanwords (henceforth loan vowels) are in general similar in terms of vowel qualities and vowel length, confirming the similarity principle assumption. Nonetheless, it will be shown that acoustic qualities of native vowels are more stable than that found in the measurements of the same vowels in loanwords. Furthermore, durational differences are shown to exist between vowels of native words and those of loanwords in such a way that native vowels are longer in duration than the same loan vowels. On the whole, the present study gives an insight into the perceptual nature of mapping and matching shared vowel sounds between the two languages in the vowel space based on phonetic/acoustic approximation.

This paper is structured as follows. It starts with a general review of the known approaches to the study of loanword phonology, including a review of previous studies on Arabic loanword phonology as well as a description of the 
Arabic vowel inventory system and an outline of the current research goals and questions. The following section outlines the method of the study. Results are presented in the next section, followed by a discussion of the presented results. The final section concludes the study.

\section{Literature review}

Three approaches to the study of sounds in loanwords have been proposed. The first is the phonologically-based approach of loanword adaptation which is held by many linguists and phonologists (e.g., Hyman, 1970; Hock, 1988; Davis, 1994; Ito and Mester, 1995; Jacobs and Gussenhoven, 2000; Davis and Kang, 2003; LaCharité and Paradis, 2005; Paradis and LaCharite, 1997, 2011). Proponents of phonological adaptation maintain that loanword adaptation is based on phonological approximation rather than on phonetic/acoustic or perceptual approximation. Under the phonological view of adaptation, borrowers of a foreign phoneme attend to the mental representations of that phoneme in their native language system based on phonological features available at their disposal, referred to as category proximity (LaCharite and Paradis, 2005). That is, in loanword adaptation of a foreign language sound for instance, speakers will opt for the native language sound that shares the close phonological features of the borrowed phoneme (category proximity) rather than the sound that is phonetically or acoustically more similar to the foreign phoneme in terms of how it is perceived by speakers (phonetic proximity). LaCharité and Paradis (2005) provide abundant examples in support of category proximity over phonetic proximity, for instance, Spanish speakers adapt English voiced stops such as /b/, /d/, and /g/ as voiced stops in spite of the fact that Spanish speakers generally perceive the English voiced stops as the voiceless stops /p, t, k/. That is, although English voiced stops are perceived phonetically as voiceless for Spanish speakers in general, borrowers adapt the voiced English stops as voiced based on feature approximation and not as voiceless based on perception approximation. The main point under this view is that the process of loanword adaptation is first and foremost phonological that upheld to the speakers' L1 mental representations and feature categorizations.

On the other hand, the phonetically-based approach to loan sounds adaptation assumes that adaptation occurs at the phonetic/perception level (i.e., not at the phonological level). Proponents of this model, such as Silverman (1992), Peperkamp and Dupoux (2003), Peperkamp (2005), Peperkamp, Vendelin and Nakamura (2008), argue that borrowers do not have access to the underlying form of the borrowed foreign structure, and because of that they map the foreign sounds they hear to the closest phonetic counterpart in their native language inventory system depending mainly on phonetic similarity (i.e., phonetic proximity). That is, adaptation is based on how borrowers perceive a foreign language sound signal through the native language perception system. Since the native perception system is finely attuned to native sounds and signals, this always results in misperception and therefore distortion of the borrowed sound (Silverman, 1992; Peperkamp and Dupoux, 2003; Peperkamp, 2005). Peperkamp et al. (2008) provide an example 
from Japanese adaption of English and French loanwords where words with a final nasal phoneme [n] are adapted differently. In Japanese, French words with a final nasal are adapted with an epenthetic final vowel while English words with a final nasal are adapted without epenthesis. Differences in Japanese adaptation of English and French loanwords were attributed to the phonetic/acoustic differences between English and French words that Japanese speakers perceive at the phonetic level. Under this approach, loanword adaptation originates from salience and perceptual similarity. In other words, the acoustic signal of a foreign sound is perceived and filtered through the native language perception system at the phonetic/perception level, resulting in the changes observed in the process of loanword adaptation.

A third approach to loanword adaptation stands in between the phonological approach and the phonetic approach. This is called the perception-phonology approach in which both phonetics and phonology are considered to play roles in adaptation (Silverman, 1992; Yip, 1993, 2006; Steriade, 2001; Kang, 2003; Kenstowicz, 2003, 2007; Gerrits and Schouten, 2004; Shinohara, 2006; Boersma and Hamann, 2009). Under this approach, it is assumed that a foreign sound is first perceived at the phonetic level, the outcome of which serves as an input to the phonological level where it is processed through native phonological grammar and constraints, resulting in an adapted output form. The advantage of the perceptionphonology model is that it accounts for phonological processes that are peculiar to loanwords but never attested in native words (Silverman, 1992; Yip, 2006; Boersma and Hamann, 2009). There are also other approaches to loanword adaptation in which extra-linguistic factors are considered to affect adaptation such as orthography and bilingualism (Adler, 2006; Davis and Cho, 2006; Smith, 2006). Out of all of these approaches, the current study is limited to focus on the major approaches to the study of loanword phonology, namely the phonological approach and the phonetic approach, excluding approaches that consider extra-linguistic factors in the process of loanword adaptation which are beyond the scope of the present study.

The direction of the context of this debate in the literature of loanword phonology is twofold. On one hand, the process of adaptation is originally triggered by lack of similarities found between L2 and L1 due to fundamental differences in the linguistic systems of the two languages that borrowers express in the form of sound or structural changes. On the other hand, such changes originate from factors that are either representationally (phonologically) grounded or factors that are perceptually (phonetically) grounded, if not from a combination of these two types of factors all together. Clearly, this debate takes for granted that adaptation is only required when two languages lack similarity or do not share certain sounds or structures due to shortage or differences. Nonetheless, as noted by Davis (1994) the mere notion of similarity between two languages in sharing two similar sounds does not guarantee that it will be adapted without any change. While it is clear from the debate that change in adaptation usually takes place when there are certain foreign sounds or structures that do not conform to the native linguistic system, it is not completely clear if change would be void for granted for foreign sounds or structures that do conform to the native linguistic system. Hence, the context this 
study tries to fulfil. The current study aims to contribute to this debate by taking a fresh look at how sounds shared by two different language systems are adapted. This is important for two reasons. First, the issue of adaptation of similar sounds has been largely overlooked in the study of loanword phonology, and it has not been thoroughly discussed in the literature. Second, exploring adaptation of similar sounds can shed light on which approach to adaptation could be more efficient to account for the issue. That is, without any change in adaptation of similar sounds in two different languages, adaptation of similar sounds is more likely to take place at the perceptual level. Simply put, mapping two similar sounds is based on the acoustic signal of the foreign sound, assuming that the signal is perceived without discrimination since the two sounds are shared by the two systems. However, the opposite would mean that adaptation of similar sounds is more likely to take place at the phonological level since the loan sound and the native sound are not perceived similarly by borrowers although the two sounds are shared by the two language systems. To that end, I examine English-based loanwords in Arabic by investigating how Arabic speakers adapt and process shared vowel sounds between the two language systems as well as discussing the implications of the findings of this inquiry for phonetic and phonological theories.

\subsection{Previous studies}

The Arabic language and its varieties have been studied within the field of loanword phonology from different perspectives. In general, previous studies on Arabic loanword phonology fall into two categories. First, earlier studies that focused on segmental changes in lexical borrowings and the associated phonological processes during adaption, such as sound change and substitution (Heath, 1989; Araj, 1993; Hafez, 1996; Al-Saqqa, 2001). Second, recent studies that have been concerned with supra-segmental phonology, such as gemination, stress and prosodic structures in phonological adaptation of loanwords (Jarrah 2013; Davis and Ragheb, 2014; Guba 2016; Al-Athwary, 2017). The current study is different from previous studies on Arabic loanword phonology in two aspects. First, the current study focuses exclusively on similarity in vowel adaptation and how loan vowels versus native vowels are processed and produced by Arabic speakers. The motive behind this concentration is that unlike consonants, vowels can be measured acoustically in terms of duration and formant measurements, which can shed light on the nature of the adapted sounds. Second, the present study examines loan vowels produced by Arabic speakers and checks them against their native counterpart vowels, and not against the original sounds produced by speakers of the source language. The rationale behind this focus is that similarity or discrepancy between adapted vowels and native vowels can provide an indication of the extent to which borrowers map and process loan vowels in accordance with the general approaches to the study of loanword phonology. Previous studies in general have focused on the distance between the original sound of the source language and the adapted sound of the recipient language while the current study focuses on the distance between the adapted sound and the mapped 
native counterpart sound by speakers within the recipient language. Thus, the present study tries to give an insight into how shared loan sounds and their native counterpart sounds are processed by borrowers.

\subsection{Arabic phonemic inventory}

Generally speaking, Arabic is marked by a rich consonantal system but a much simpler vowel system. The Arabic variety of speakers in the present study is a Saudi Arabic variety spoken in the southwest of Saudi Arabia in the city of Abha (i.e., Southwestern Saudi Arabic SSA). The consonant system of this Arabic variety consists of 27 consonants. The number of consonants in Arabic varieties ranges between 25 to 30 consonants depending on the spoken Arabic variety (Holes 2004). Like other Arabic varieties, SSA lacks the English voiceless stop /p/, the English voiceless fricative $/ \mathrm{v} /$, and the velar nasal consonant $/ \mathrm{y} /$, while all other English consonants are shared by the two consonant systems. Shared consonants are matched to their native counterparts without any discrepancy. Nonetheless, English consonants that do not occur in Arabic are mapped to their closest Arabic phoneme. As shown by previous studies on different Arabic varieties (e.g., Guba 2016), which is also true for Saudi and Gulf Arabic varieties in general, the English voiceless phoneme $/ \mathrm{p} /$ is usually mapped as the voiced stop /b/ while the English voiced phoneme $/ \mathrm{v} /$ is usually mapped as the voiceless fricative /f/. Since the English velar nasal consonant $/ \mathrm{y} /$ does not occur in Arabic, it is usually mapped as either the nasal phoneme $/ \mathrm{n} /$ or as the consonant cluster $/ \mathrm{ng} / \mathrm{in}$ words such as king.

The Arabic vowel system is far much simpler than its consonant system. In general, the vowel system in Standard Arabic and most Arabic verities consists of three sets of pairs, three short vowels and three long counterpart vowels. This means a vowel system with only symmetrical six vowels in comparison with the English vowel system that consists of 12 pure vowels, excluding diphthongs and triphthongs. Other than that, Arabic varieties differ as to whether the two standard diphthongs /aw/ and /ay/ are monophthongized as one long vowel or not. The Arabic variety in the present study consists of eight vowels. These are the three short vowels /i, u, a/ and their long counterparts /ii, uu, aa/. The diphthongs /aw/ and /ay/ are monophthongized as /oo/ and /ee/, respectively. Clearly, vowels are much more prone to different adaptation processes due to the discrepancy between the two vowel systems. As noted by Guba (2016) on English loanwords in Jordanian Arabic, one to one matching is not possible between the two vowel systems. What speakers do most of the time is that foreign vowels are mapped to their closest native vowels based on phonetic or phonological characteristics. Guba (2016) cites numerous examples of vowel adaptations such as that the high front vowels /I/ and /i:/ are typically mapped as /i/ and /ii/ while the back vowels / / /, /u:/, and $/ \mathrm{s} / /$ are realized as $/ \mathrm{u} /, / \mathrm{uu} /$, or /oo/, respectively. Other vowels such as /æ/ and /a:/ are typically realized as /a/ and /aa/, respectively. Nonetheless, this is not what happens all the time for borrowers as different factors come to play roles in vowel adaptation such as harmony, stress, prosodic structures, and morphology, resulting in various realizations of vowels in loanwords adaptation (Guba, 2016). Given the limited vowel system in Arabic (the recipient language) compared to the rich vowel 
system of English (the source language), patterns of vowel adaptation can shed light on many issues that pertain primarily to nativization and integration of foreign/loan sounds, an issue the current study intends to tackle in terms of how loan vowels are adapted in comparison with their native counterparts.

\subsection{Current research goals}

Whether adaptation is actually active or simply is not required when it comes to adaptation of shared sounds between two different languages has not been sufficiently explored. The present research therefore addresses this issue in particular and reports on how shared vowels between English and Arabic are mapped and adapted by Arabic speakers in selected English-based loanwords. This is done in comparison with how the same speakers produce vowels occurring in native words (native vowels) in correspondence with their productions of similar vowels that occur in loanwords (loan vowels). Based on reports of previous studies on typical mappings of shared vowels in Arabic varieties with English, such as Guba (2016), as well as the researcher's knowledge of the shared vowels between the two languages as a bilingual speaker, the research aims at examining only shared vowels while excluding all other types of vowels that are not shared by the two vowel inventories. Thus, the research identifies five vowels that are in correspondence between the English vowel system and the Arabic vowel system. The shared vowels between English and the Arabic variety under examination in this research are generally long vowels. These vowels are outlined in the table 1 below (note that the study uses a colon for English long vowels and a double symbol for Arabic long vowels. This is conventionally how Arabic long vowels are usually represented in the literature.)

Table 1. Vowels in correspondence between English and Arabic vowel inventories

\begin{tabular}{ll}
\hline English vowels & Arabic Vowels \\
\hline li:/ & /ii/ \\
/u:/ & /uu/ \\
/o:/ & /oo/ \\
/eI/ & /ee/ \\
læ/ & /aa/ \\
\hline
\end{tabular}

All other vowels in the two languages are not shared by the two phonemic inventories. Hence, they are excluded. However, note that the three Arabic short vowels $/ \mathrm{i}, \mathrm{u}, \mathrm{a} / \mathrm{can}$ be considered to be in correspondence with the English short vowels $/ \mathrm{I}, \mho, æ /$, respectively. Nonetheless, short vowels are excluded in the present research for three reasons. First, not all Arabic long vowels have short symmetrical versions, for example /ee/ and /oo/ are monophthongized diphthongs pronounced as one vowel sound in many spoken Arabic varieties but they do not have short versions. The exclusion of short vowels avoids this inconsistency across the vowels under study. Second, long vowels allow a greater degree of control over the formants and length measurements, providing a better understanding of the acoustic 
properties of the vowels under probe. Third, generalizations on the behavior of long vowels can be extended to their short symmetrical versions without the need to examine the short versions in particular.

The current research seeks answers to the following major research questions:

I. How and to what extent are shared vowels between English and Arabic vowel inventories adapted in English-based loanwords? Do shared vowels invoke any form of adaptation by borrowers or simply adaptation is not required in such a situation?

II. What are the similarities and differences between loan vowels in comparison with their native counterpart vowels in terms of acoustic properties? Are loan vowels and native vowels processed and produced by speakers similarly or differently?

\section{Method}

\subsection{The word list}

The loanwords compiled in the present study occur in ordinary and daily life speech of the participants. The influx of English loanwords has influenced a lot of aspects of Saudi social life mostly because of modernization and the immense influence of Western-American lifestyle on social domains such as cafes, restaurants, brands, movies, education, travel, and so on. Five loanwords were chosen to represent the five English long vowels under examination. Similarly, five native words were chosen to represent the same vowels in Arabic. The phonological environment in each set of loan and native words was carefully considered as much as possible in order to avoid variation that may occur during acoustic analysis. The word list is outlined in the following table. The targeted vowel in each word is underlined. Transcription of the English loanwords is based on the Cambridge Online Dictionary (2021).

Table 2. Targeted long vowels in loanwords and native words

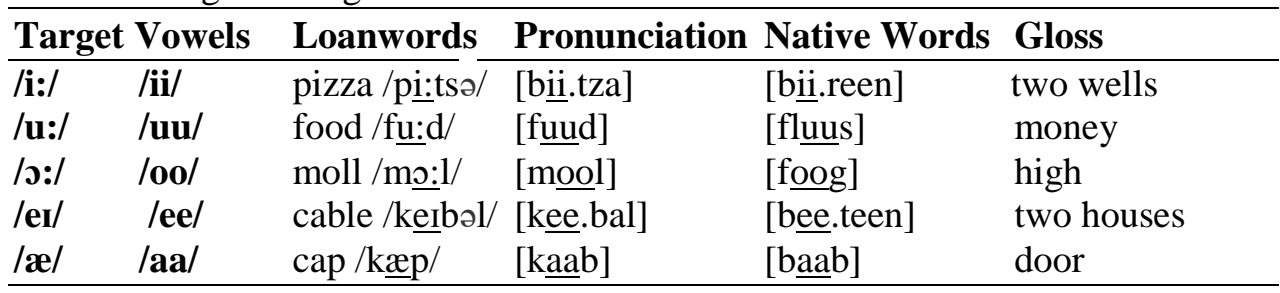

The word list was carefully selected and designed to represent the target vowels that occur in both vowel systems. At the same time, syllabification patterns for each vowel in the selected words were carefully considered. For example, the long loan vowel /ii/ in the loanword [bii.tza] clearly takes place in the penultimate syllable. Similarly, the native counterpart vowel/ii/ in the native word [bii.reen] occurs in the same non-final word position. This will enable us to avoid any variation that may occur due to syllable position in the word. Note that the high back vowel /uu/ in the native word /fluus/ occurs after an onset consonant cluster 
which is unavoidable since all native words with the long vowel /uu/ occurs in words with consonant clusters that result from high vowel deletion, a salient phonological process in the language. (The word is underlyingly disyllabic as /fu.luus/ but it surfaces as [fluus] with an onset consonant cluster after high vowel deletion, which is a well-known phonological process in several current Arabic varieties.)

\subsection{Participants}

The participants in the current study were 22 male native speakers of Arabic residing in Saudi Arabia in the city of Abha. All participants are speakers of the same Arabic variety spoken in that area. Participants' age ranged between 20 to 40 years old. All participants were monolingual Arabic speakers. Nonetheless, as is the case in many countries worldwide, the participants had been taught English at school. Yet, they had not been taught English prior to school before the age of 6 years. In addition, it should be noted that the study of English at school does not appear to make them able to speak English fluently nor able to understand it without help.

\subsection{Procedure}

Productions of the participants were recorded in a quiet and comfortable environment. First, each participant was provided with instructions and information on how to perform the task and produce the required word productions before the start of the recording session. Then, each participant was presented with pictures resembling the target loanword and was asked to figure out which word is used to refer to that picture. This was done in order to rule out the effect of orthography. Once the participant defined the target loanword, he was asked to repeat the word three times. Each round of productions for each word was recorded and saved as an audio file for the acoustic analysis. Another recording session following the same steps was conducted for the native word list. Each session took around 10 minutes per participant.

\subsection{Acoustic Analysis}

The extracted productions of the word list from recordings reached a total of 660 tokens. Each token was analyzed through PRAAT version 6.1.41 (Boersma and Weenink, 2021). The vowel produced in each token was identified as the target of the PRAAT analysis (Figure 1). Thus, the vowel in each token was analyzed in terms of three acoustic properties at two temporal points of time: vowel duration, the first formant F1 (height), and the second formant F2 (advancement). Measuring the vowel at two temporal points enabled us to accurately detect if there were any changes in the vowel properties during its onset or at its peak. The first temporal point T1 represented the first third of the vowel duration (onset) while the second temporal point $\mathrm{T} 2$ represented the second third of the vowel duration (peak).

In order to identify the general properties of the examined vowels, means of each formant measurements (i.e., F1 and F2) were calculated for the three 
productions of each word by each participant. Then, the average of the means of all formant measurements of all participants for each vowel was calculated to be used in vowel plotting charts. The mean vowel duration for each set of productions per speaker was also measured for the measurements of the duration of each vowel in the durational analysis. Then, the overall average of the mean vowel duration by all speakers for each vowel was calculated for an overall comparison between loan and native vowels in terms of vowel length.

The acoustic analysis aims to achieve two major goals. First, the formant measurements will give us an indication of the degree of phonetic similarity between the loan vowels in comparison with the native vowels in the vowel space. This is further visualized in the analysis using vowel plotting charts through which vowels can be examined for acoustic similarity at two temporal points. Second, the durational analysis of vowels will enable us to further examine the quality of each vowel in the corpus based on vowel length. This will also allow us to make further comparisons between loan and native vowels in terms of whether or not they are treated similarly by speakers.
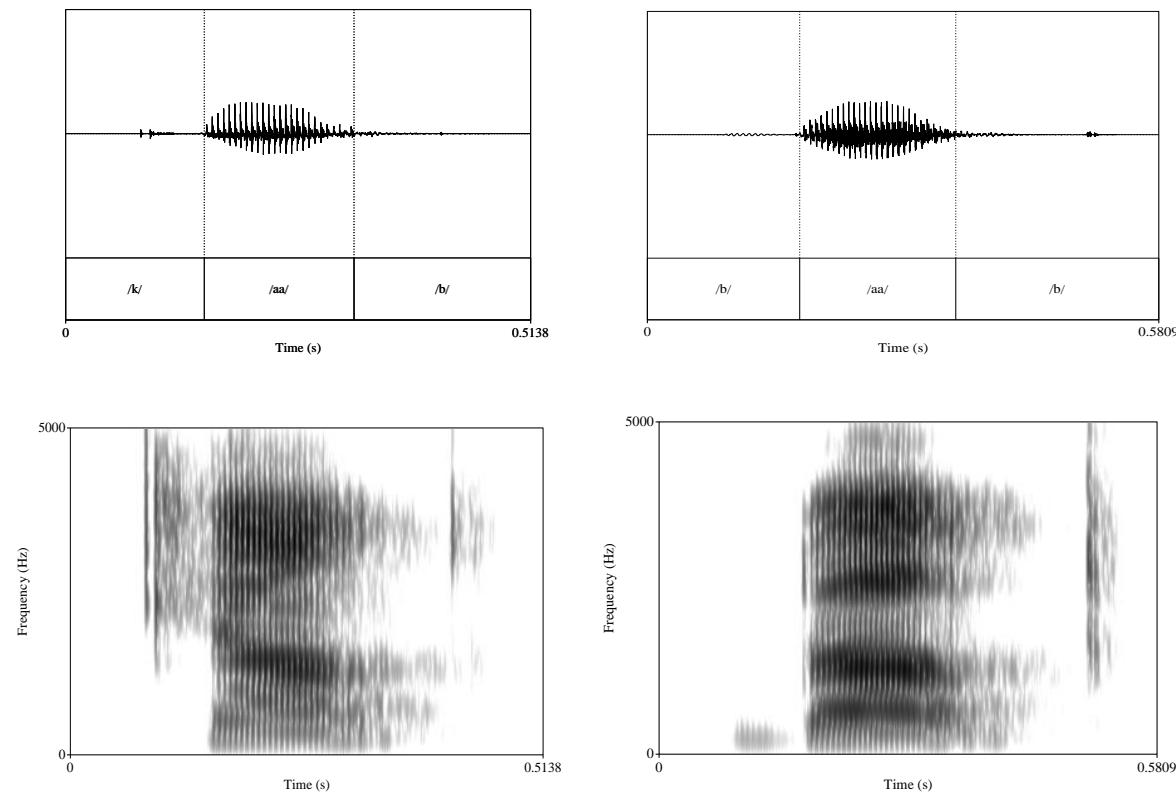

Figure 1. Spectrograms and waveforms of the loanword /kaab/ 'cap' and the native word /baab/ 'door' as produced by one speaker. The target vowel /aa/ is identified.

\section{Results}

The results of the analyzed data are presented based on two criteria. The first criterion is the measurements of vowel quality in terms of its acoustic properties in hertz $(\mathrm{Hz})$ for vowels that occur in native words (i.e., native vowels) and counterpart vowels that occur in loan words (i.e., loan vowels). For more accuracy, measurements are calculated at two temporal points: T1 (i.e., the first third of the vowel) and T2 (i.e., the second the third of the vowel). The second criterion is the 
measurements of vowel duration according to the length of the produced vowel in milliseconds (ms) for native vowels and loan vowels. Mean values are presented based on an overall calculations of tokens across all participants.

\subsection{Vowel quality for native vowels}

Figure 2 shows mean F1 and F2 values across vowels that occur in native words (i.e., native vowels) in two temporal points: $\mathrm{T} 1$ and $\mathrm{T} 2$. No significant difference is observed for these vowels in terms of mean formant values during T1 and T2. It is remarkable that formant values for native vowels are stable during the two phases of measurements. The mean F2 value for the high front vowel /ii/ is between 2100 $\mathrm{Hz}$ to $2300 \mathrm{~Hz}$ during T1 and T2 while its $\mathrm{F} 1$ mean value is between $300 \mathrm{~Hz}$ to 350 $\mathrm{Hz}$ during T1 and T2. F2 mean value for the high back vowel /uu/ is around 1100 $\mathrm{Hz}$ while its $\mathrm{F} 1$ mean value is almost at $400 \mathrm{~Hz}$ during both temporal points. The mid front vowel /ee/ is around $1900 \mathrm{~Hz}$ in its F2 mean value while its F1 mean value is at $450 \mathrm{~Hz}$ during $\mathrm{T} 1$ and T2. The mid back vowel /oo/ is at $900 \mathrm{~Hz}$ for its $\mathrm{F} 2$ mean value and at $500 \mathrm{~Hz}$ for its $\mathrm{F} 1$ mean value during both temporal points. The F2 mean value for the low central vowel /aa/ is around $1300 \mathrm{~Hz}$ and around $650 \mathrm{~Hz}$ for its $\mathrm{F} 1$ mean value during $\mathrm{T} 1$ and $\mathrm{T} 2$.

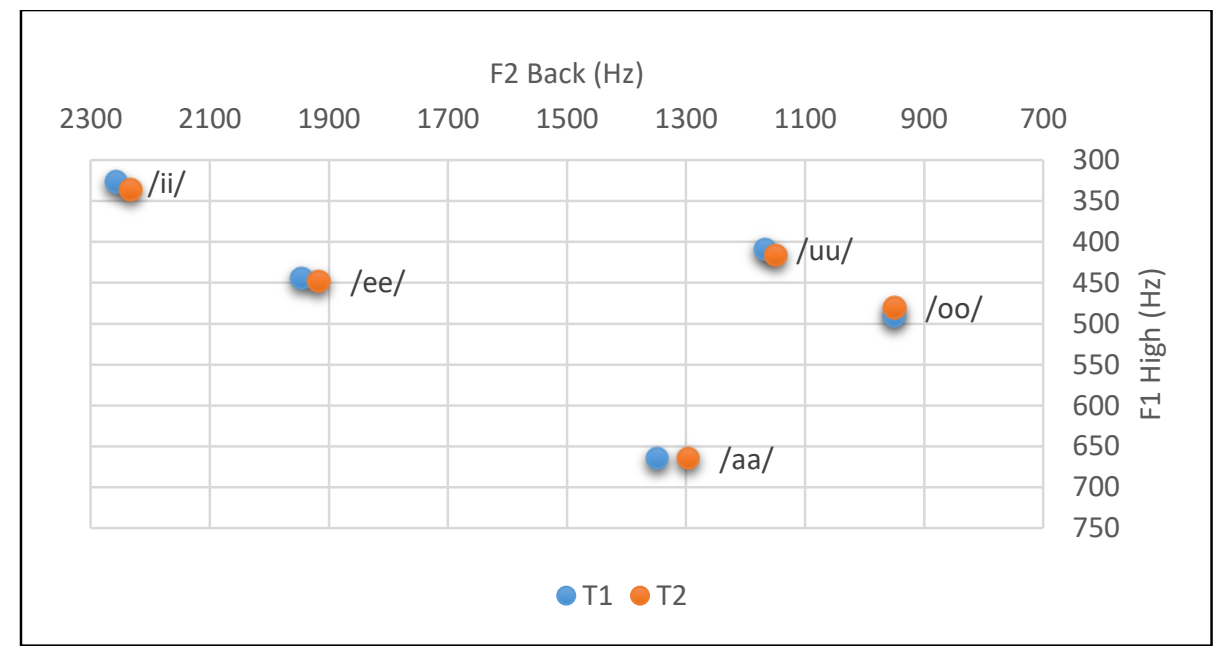

Figure 2. Mean formant values F1 and F2 in (Hz) for native vowels

\subsection{Vowel quality for loan vowels}

Figure 3 shows mean F1 and F2 values for vowels that occur in loan words (i.e., loan vowels) during the two temporal points: $\mathrm{T} 1$ and $\mathrm{T} 2$. There are no significant differences between loan vowels and native vowels in terms of their height or advancement while native vowels disparity in formant measurements of loan vowels appears to take place during $\mathrm{T} 1$ and $\mathrm{T} 2$. That is, contrary to native vowels, the loan vowels are notably unstable at the two temporal points of measurement as loan vowels appear to be more shifted at the peak of the vowel (i.e., T2) with 
different height and advancement from that measured at the onset of the vowel (i.e., T1). Furthermore, Figure 3 indicates that the loan low vowel /aa/ appears to be more lowered than the native low vowel /aa/ at both temporal points, with no evident explanation of why this is the case at present. Overall, Figure 3 shows the general pattern of the fluctuation of the loan vowels during the two temporal points of formant measurements.

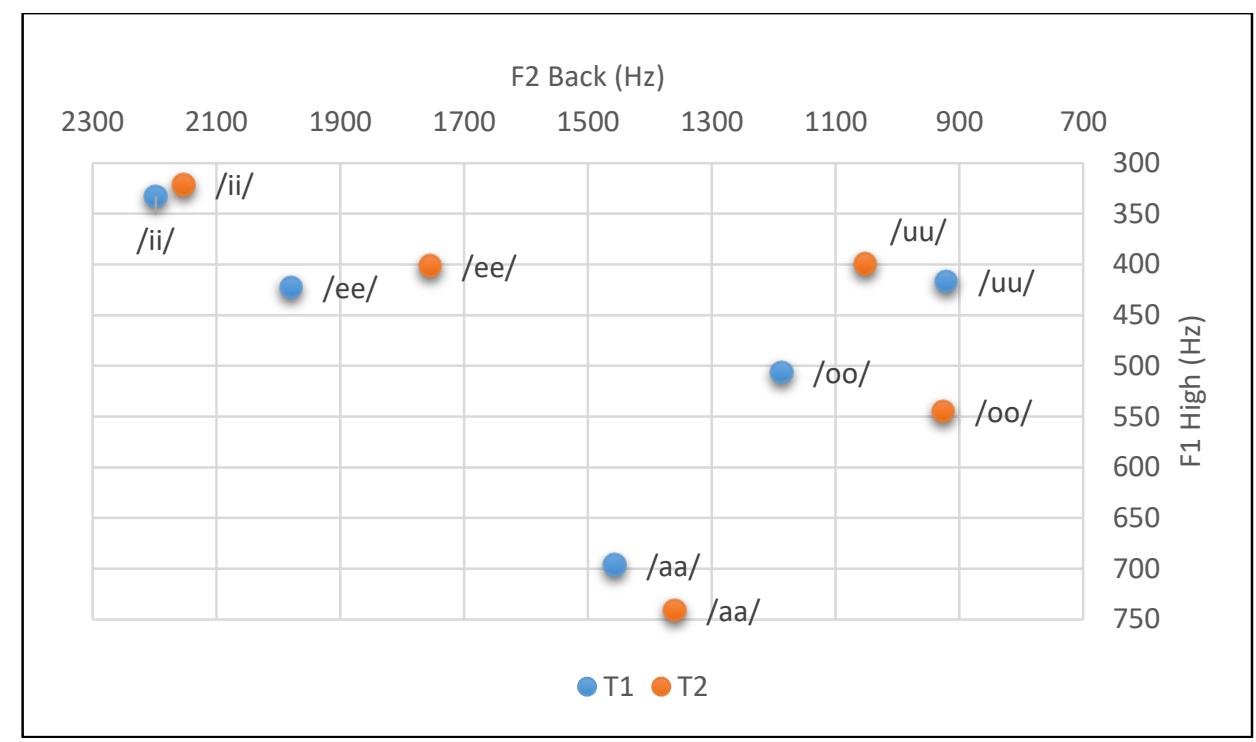

Figure 3. Mean formant values F1 and F2 in (Hz) for loan vowels

\subsection{Vowel duration for loan vowels vs. native vowels}

Figure 4 shows the durations of loan and native vowels averaged across all speakers. As can be noticed, the mean duration of loan vowels differs from that of native vowels. Although the difference is not significant, native vowels in general are longer in duration than loan vowels. While the length of vowels in general is sensitive to the phonetic environment, differences in length of the examined vowels in the present analysis are attributed to the effects of nativization and internalization. Studies on vowel duration such as Jacewicz, Fox, and Salmons (2007), Mok (2011), and Adam (2014) have reported that vowel length is influenced by the consonantal context. Vowels that precede voiced consonants appear to be longer than vowels preceding voiceless consonants (Jacewicz et al., 2007). In this analysis, the low vowel /aa/ in native and loan words / $/ \mathrm{baab} / \mathrm{and} / \mathrm{kaab} /$ precedes the voiced consonant $/ \mathrm{b} /$, and yet the native vowel appears to be longer in duration than the loan vowel across all speakers. The second example shows that although the back vowel /uu/ is preceded by the voiceless consonant /s/in the native word /fluus/ 'money', it appears to be longer in duration than in the loanword /fuud/, despite the fact that it is followed by the voiced consonant /d/. Overall, Figure 4 indicates that differences in vowel duration were manifested across all inspected vowels and that the phonetic environment effect does not seem to affect length here. 


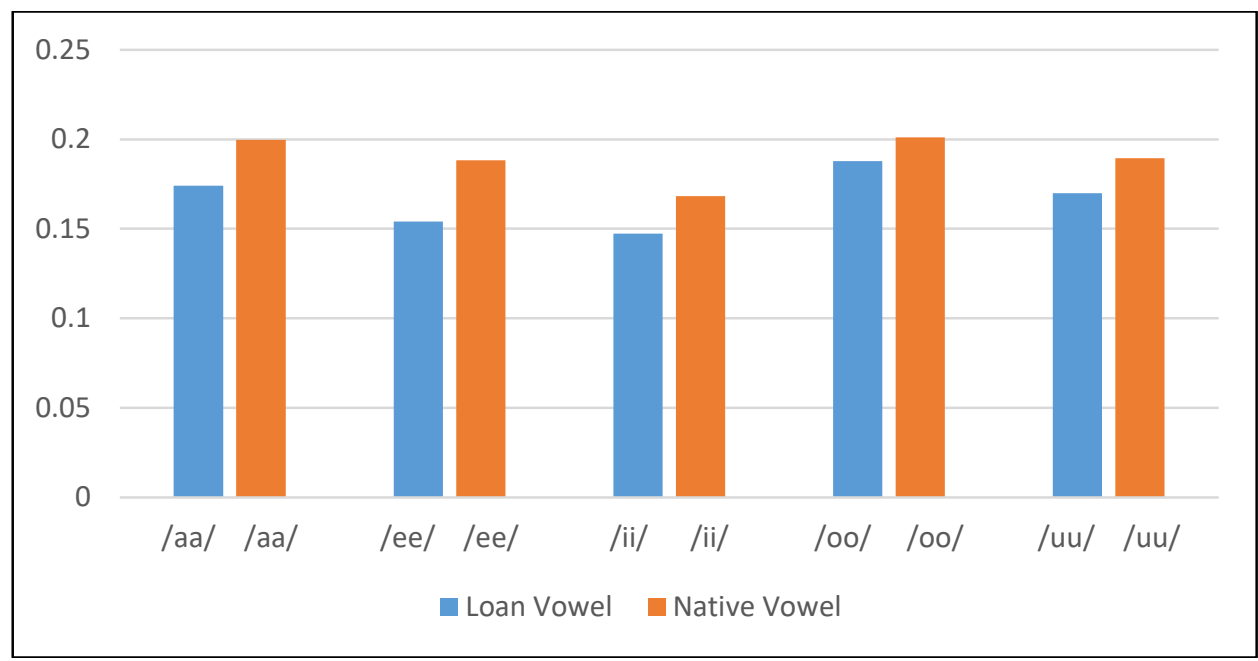

Figure 4. Mean vowel duration in (ms) for loan and native vowels

To summarize, two main results are demonstrated in the analysis of the same vowels that appear in loan words (loan vowels) and those appearing in native words (native vowels). The first result is that formant measurements (F1 and F2 values) of native vowels appear to be more stable than those of loan vowels during the onset and peak of the vowel (T1 and T2 periods). The second result is that native vowels appear to be longer in duration than their counterpart loan vowels.

\section{Discussion}

In an answer to the research questions raised earlier in the study, it can be said that the present results support the conclusion that even shared sounds between different vowel inventories in different languages do invoke some sort of adaptation. This adaptation appears to be based on perception and phonetic proximity in the present results. This might be due to the fact that the Arabic vowel inventory is limited to a few set of pair vowels where speakers map vowels to the closest native counterpart based on signals available at their disposal. While this answers the first research question to some extent, answer to the second research question requires much more detailed explanations. This is demonstrated in the following.

The general findings of the present study show that vowels in loanwords are somehow processed and produced differently from the same vowels that appear in native words. This is shown in terms of vowel quality formant measurements as well as vowel duration across all speakers in the present results. While the attested differences between the first two formant measurements are not significant for the same loan and native vowels, it is evident that there is discrepancy between formant measurements of vowels during the two temporal points of measurement. In the case of native vowels, mean values of F1 and F2 seem to be stable during T1 and $\mathrm{T} 2$. However, this is not the case for loan vowels whose formant values appear to 
be fluctuating to some degree during the two temporal points. The reason why the first two formants values of loan vowels are not as stable as those of native vowels is possibly due to the process of nativization in which vowels in loanwords undergo a constant process of matching and mapping to the closest native vowels. This conclusion supports the assumption that similarity in loanword phonology is gradient rather than defined.

In terms of duration differences between the same vowels that appear in loanwords compared to those appearing in native words, the present results show that native vowels are generally longer in duration than loan vowels. There are two possible reasons why this is the case in the present results. The first and the most important one is that it could be possible that loanwords are processed without emphasis or stress information whereas native vowels are loaded with full information of stress placement, and thus receiving complete length, assuming that stress affects length and loudness of the vowel. (Note that like English, most spoken Arabic varieties have quantity sensitive stress systems. The question of why borrowers are unable to perceive stress in loan words under this assumption is beyond the scope of the present study.) Another possible reason might be that duration differences can be linked to the stability of formant values for native vowels in contrast to the fluctuations of formant values in loan vowels as shown earlier in the present results. While these explanations are not sufficient enough in explaining the observed duration differences, it should be noted that vowel length distinction between loan and native vowels seems to be maintained by all speakers across all vowels.

It is evident that differences in vowel properties in terms of the first two formants values are not significant which would suggest that these meticulous differences stem from perception/phonetic approximation as speakers try to match vowels in loanwords to their closest native counterparts. Thus, vowel qualities in loanwords will be as close as possible to their native equivalents but should not be identical, an issue that can be further investigated in extended studies.

\section{Conclusion}

The ultimate goal of the present study was to examine how the same vowel sound that appears in a loanword is processed and produced by speakers in comparison with the same vowel appearing in a native word. To that end, productions of English-based loanwords by Arabic speakers were obtained and analyzed acoustically and checked against productions of the same sounds in native words. The analysis focused on the examination of vowel quality and vowel duration. In terms of vowel quality, the presented results revealed that while formant measurements of the first two formants were similar to a large degree in loan and native vowels, it has been shown that formant measurements of native vowels appeared to be stable during the two temporal points of measurements (i.e. the whole vowel duration during its onset and its peak). By contrast, formant measurements of loan vowels appeared to be fluctuating to some degree during the two temporal points of measurements. In the present study, this discrepancy was attributed to nativization and phonetic approximation as speakers consistently try 
to map loan vowels to their closest native counterparts as much as possible even for shared or similar vowels. Furthermore, duration differences between loan vowels and native vowels were found in the present results. It has been shown that native vowels have a longer duration than loan vowels across all speakers. Stress and emphasis effects were proposed to account for such discrepancy in vowel length. Finally, it should be noted that the study was limited by the number and gender of speakers as well as the number of the stimuli in the word list. Future work should examine short vowels and include female participants to see if genderrelated effects can be found. Further research should be carried out to investigate data from other varieties and languages to verify the presented patterns observed in the adaptation of shared sounds in loan sounds adaptation.

Musa Alahmari

Faculty of Languages \& Translation, Department of English.

King Khalid University, Saudi Arabia.

ORCID: 0000-0001-5211-9810

Email: alahmari@kku.edu.sa

\section{References}

Adam, Hisham. (2014). 'Acoustical analysis of vowel duration in Palestinian Arabic speaking aphasics'. American Journal of Psychiatry and Neuroscience, 2(1):13-17. doi:10.11648/j.ajpn.20140201.13.

Adler, Allison. (2006). 'Faithfulness and perception in loanword adaptation: A case study from Hawaiian'. Lingua, 116(7):1024-1045.

Alahmari, Musa. (2021). 'Prosodic adaptation of superheavy syllables in Arabic loanwords in Turkish: An optimality-theoretic analysis'. King Abdulaziz University Journal of Arts and Humanities, 28:581-596.

Al-Athwary, Anwar A. H. (2017). 'The phonotactic adaptation of English loanwords in Arabic'. Arab World English Journal, 8(3):392-406. doi: https://dx.doi.org/10.24093/awej/vol8no3.25

Al-Saqqa, Samar. (2001). English loanwords in the language of Arabic advertising in Jordan. Unpublished MA Thesis, University of Jordan, Amman, Jordan.

Araj, Samia. (1993). Foreign words in the Arabic press: A study of the impact of western languages on Arabic. Published Ph.D. Dissertation, The University of Texas, Austin.

Boberg, Charles. (2020). 'Foreign (a) in North American English: Variation and change in loan phonology'. Journal of English Linguistics, 48(1):31-71.

Boersma, Paul and Silke Hamann. (2009). 'Loanword adaptation as firstlanguage phonological perception'. In Andrea Calabrese and W. Leo 
Wetzels (Eds.), Loan Phonology, 11-85. Amsterdam: John Benjamins Publishing Company.

Boersma, Paul and David Weenink. (2021). Praat: Doing phonetics by computer. http://fon.hum.uva.nl/praat/.

Cambridge Online Dictionary. (2021). Cambridge University Press. https://dictionary.cambridge.org

Davis, Stuart. (1994). 'Loanwords: Phonological treatment'. In Ronald Asher (Ed.), The Encyclopedia of Language and Linguistics, 4:2273-2276. New York and Oxford: Pergamon Press.

Davis, Stuart and Mi-Hui Cho. (2006). 'Phonetics versus phonology: English word final /s/ in Korean loanword phonology'. Lingua, 116(7):1008-1023.

Davis, Stuart and Hyunsook Kang. (2006). 'English loanwords and the wordfinal [t] problem in Korean'. Language Research-Seoul, 42(2):253.

Davis, Stuart and Marwa Ragheb. (2014). 'Geminate representation in Arabic'. In Samira Farwaneh and Hamid Ouali (Eds.), Perspectives on Arabic linguistics $X X I V-X X V: 3-19$. Philadelphia: John Benjamins Publishing Company.

Gerrits, Ellen and Marten E.H. Schouten. (2004). 'Categorical perception depends on the discrimination task'. Perception and Psychophysics, 6:363378.

Guba, Mohammad N. A. (2016). Phonological adaptation of English loanwords in Ammani Arabic. Published Ph.D. Dissertation, University of Salford.

Hafez, Ola. (1996). 'Phonological and morphological integration of loanwords into Egyptian Arabic'. Égypte Monde Arabe, 28:383-410.

Haunz, Christine. (2004). 'The role of perception in the adaptation of loanwords'. The University of Edinburgh. http://www.lel.ed.ac.uk/ pgc/archive/2002/proc02/haunz02.pdf

(Retrieved on 13, April, 2021)

Heath, Jeffrey. (1989). From code-switching to borrowing: Foreign and diglossic mixing in Moroccan Arabic. London: Kegan Paul International.

Hock, Hans. (1988). Principles of historical linguistics. Mouton de Gruyter: Berlin.

Holes, Clive. (2004). Modern Arabic: Structures, functions, and varieties. Washington, DC: Georgetown University Press.

Hyman, Larry. (1970). 'The role of borrowing in the justification of phonological grammars'. Studies in African Linguistics, 1:1- 48.

Itô, Junko and Armin Mester. (1995). 'The core-periphery structure of the lexicon and constraints on re-ranking'. In Jill Beckman, Suzanne Urbanczyk and Laura Walsh Dicky (Eds.), University of Massachusetts Occasional Papers in Linguistics, 18: 181-209. University of Massachusetts, Amherst.

Jacewicz, Ewa, Robert A. Fox, and Joseph Salmons. (2007). 'Vowel duration in three American English dialects'. Am Speech, 82(4): 367-385. doi:10.1215/00031283-2007-024.

Jacobs, Haike and Carlos Gussenhoven. (2000). 'Loan phonology: Perception, salience, the lexicon and OT'. In Joost Dekkers, Frank van der Leeuw, and 
Jeroen van de Weijer (Eds.), Optimality theory: Phonology, syntax, and acquisition, 193-210. Oxford: Oxford University Press.

Jarrah, Ali S. (2013). 'English loanwords spoken by Madinah Hijazi Arabic speakers'. Arab World English Journal, 2:67-85.

Kang, Yoonjung. (2011). 'Loanword phonology'. In Marc van Oostendorp, Colin Ewen, Elizabeth Hume, and Keren Rice (Eds.), The Blackwell companion to phonology, 2258-2282. Malden, MA and Oxford: Wiley-Blackwell.

Kang, Yoonjung. (2003). 'Perceptual similarity in loanword adaptation: English postvocalic word-final stops in Korean'. Phonology, 20:219-273.

Kenstowicz, Michael. (2003). 'The role of perception in loanword phonology'. Studies in African Linguistics, 32:95-112.

Kenstowicz, Michael. (2007). 'Salience and similarity in loanword adaptation: A case study from Fijian'. Language Sciences, 29(2):316-340.

LaCharité, Darlene and Carole Paradis. (2005). 'Category preservation and proximity versus phonetic approximation in loanword adaptation'. Linguistic Inquiry, 36(2):223-258.

Lee, Dongmyung. (2009). The loanword tonology of South Kyungsang Korean. Published Ph.D. Dissertation, Indiana University, Bloomington.

Miao, Ruiqin. (2006). Loanword adaptation in Mandarin Chinese: Perceptual, phonological and sociolinguistic factors. Published Ph.D. Dissertation, Stony Brook University.

Mok, Peggy P.K. (2011). 'Effects of vowel duration and vowel quality on vowelto-vowel coarticulation'. Language and Speech, 54(4):527-545.

Natvig, David. (2017). 'A model of underspecified recognition for phonological integration: English loan vowels in American Norwegian'. Journal of Language Contact, 10: 22-55.

Paradis, Carole and Darlene LaCharité. (1997). 'Preservation and minimality in loanword adaptation'. Journal of Linguistics, 33:379-430.

Paradis, Carole and Darlene LaCharité. (2011). 'Loanword adaptation: From lessons learned to findings'. In John A. Goldsmith, Jason Riggle, and Alan C. L. Yu (eds.), The handbook of phonological theory, $2^{\text {nd }}$ Edition, 751778. Oxford: Wiley-Blackwell.

Peperkamp, Sharon. (2005). 'A psycholinguistic theory of loanword adaptations'. In Marc Ettlinger, Nicholas Fleischer, and Mischa Park-Doob (eds.). Proceedings of the 30th annual meeting of the Berkeley linguistics society. 341-352. Berkeley: Berkeley Linguistic Society.

Peperkamp, Sharon and Emmanuel Dupoux. (2003). 'Reinterpreting loanword adaptations: The role of perception'. International Congress of Phonetic Sciences, 15:367-370.

Peperkamp, Sharon, Inga Vendelin, and Kimihiro Nakamura. (2008). 'On the perceptual origin of loanword adaptations: Experimental evidence from Japanese'. Phonology, 25:129-164.

Shinohara, Shigeki. (2006). 'Perceptual effects in final cluster reduction patterns'. Lingua, 116:1046-1078. 
Silverman, Daniel. (1992). 'Multiple scansions in loanword phonology: Evidence from Cantonese'. Phonology, 9:289-328.

Smith, Jennifer. (2006). 'Loan phonology is not all perception: Evidence from Japanese loan doublets'. In Timothy J. Vance and Kimberly Jones (eds.), Japanese/Korean Linguistics, 14:63-74. Stanford: CSLI.

Steriade, Donca. (2001). 'Directional asymmetries in place assimilation: A perceptual account'. In Elizabeth Hume and Keith Johnson (Eds.), The role of speech perception in phonology, 219-250. New York: Academic Press.

Tu, Jung-Yueh. (2013). Word prosody in loanword phonology: Focus on Japanese borrowings into Taiwanese Southern Min. Published Ph.D. Dissertation, Indiana University, Bloomington.

Yip, Moira. (1993). 'Cantonese loanword phonology and optimality theory'. Journal of East Asian Linguistics, 2:261-291.

Yip, Moira. (2002). 'Necessary but not sufficient: Perceptual loanword influences in loanword phonology'. The Journal of the Phonetic Society of Japan, Special Issue on Aspects of Loanword Phonology, 6:4-21.

Yip, Moira. (2006). 'The symbiosis between perception and grammar in loanword phonology'. Lingua, 116:950-975. 